\title{
Practice of Entrepreneurial Orientation in the Governmental Sector
}

\author{
Tawfeeq Mohammed Alanazi ${ }^{1}$ \\ ${ }^{1}$ Faculty of Business Administration, University of Tabuk, Tabuk, Saudi Arabia \\ Correspondence: Tawfeeq Mohammed Alanazi, Faculty of Business Administration, University of Tabuk, Tabuk, \\ Saudi Arabia.
}

Received: June 24, 2018

Accepted: July 10, 2018

Online Published: July 19, 2018

doi:10.5430/ijba.v9n4p148

URL: https://doi.org/10.5430/ijba.v9n4p148

\begin{abstract}
The reason of conducting this research is that there is no reliable study measures entrepreneurial orientation (EO) at government entities. EO among commercial organisations is widely addressed in previous research and literature due the intense market competition where this type of organisations should invigorate and accelerate EO to lead markets. Nevertheless, there is quite small number of research works that examine EO among semi-governmental organisations. However, those research works are not sophisticated enough to measure the impact of adopting and implementing EO within governmental organisations. The four principles of EO, which are innovation, autonomy, risk-taking and pro-activeness are applied to examine the extent of implications among governmental sectors and impact of EO on an organisation's performance. Continually, organisations' performance is been identified by three elements. These are stimulating internal environmental effectiveness, ability to achieve the organisation's goals and individual ability for self-development. The research is applied among Saudi governmental sectors in Tabuk City. Measurement items and instruments adopted from previous studies. Then, the exploratory factor analysis performed to determine applicability of EO factors among governmental sectors. Exploratory factor analysis proves that some factors, such as innovation and autonomy have a significant reason to be applied. The research results show that innovation has an impact on the internal environment to stimulate internal environmental effectiveness. However, the research could not find any link between innovation, ability to achieve organisation's goals and individual ability for self-development. On the other hand, the internal environment's effectiveness and ability to achieve an organisation's goals can be increased if there is quite good margin of autonomy. Furthermore, whenever risk-taking attitude is high, individual development ability is clearly high as well. Finally, pro-activeness has a slight link with ability to achieve organisation's goals.
\end{abstract}

Keywords: entrepreneurial orientation, governmental sector, organisation performance

\section{Introduction}

Definition of EO is varied based on different schools that authors are related to. Casson (1990) considers EO as inventing new products, while Acs (1992) links the concept to small business or what is called entrepreneurship. However, a number of authors agree that the concept of EO consists of three factors: innovation, risk-taking and pro-activeness (Miller, 1983; Morris \& Paul, 1987; Covin \& Slevin, 1989). Essentially, these three components were mentioned widely and used in many previous studies. Miller (1983), for example, describes an entrepreneurial organisation and distinguishes it from a non-entrepreneurial organisation where an organisation with a high level of innovation relevantly accepts a risky market and has a plan to be proactive than any other organisation and will be described as an entrepreneurial firm. Although the previous definition is exceedingly employed, it includes only three components of EO, which force Lumpkin and Dess (1996) to expand the concept to five factors as innovation, autonomy, risk-taking, pro-activeness and competitive aggressiveness.

On the other hand, measuring an organisation's performance is subject to frequent changes in its methods based on the outcomes of each factor or measure. In this research, the focus is on three variables to measure the organisation's performance. Those variables are an effective work environment, achievement of goals and objectives, and self-development. Hofstede et al. (1990) say that an organisation's internal environment is controlled by a specific culture - the culture that can dominate both organisation and individuals' behaviour - and if there is any plan to enhance the effectiveness of the environment, managers should work first to change and transfer the existing culture. This view is shared by Martin (1992). Meanwhile, the ability to achieve the organisation's goals and objectives has an essential role in the organisation's outcomes. Thus, achieving the organisation's goals usually relies on the 
determination of the individual as well as his understanding and absorbing the proposed goals and objectives and appropriate time of presenting them (Gollwitzer, 1999). Obviously, the main source of power is skilled employees who keep an organisation up to the competition. For that reason, individuals' ability to develop themselves is quite an important factor in consolidating an organisation's performance (Van-der Merwe \& Malan, 2013). Truly, performance measurement factors vary from one organisation to another but are mostly derived from one of the three factors mentioned above.

\section{Literature Review and Hypotheses}

There was a belief that EO is about creating new products and new methods that help the local economy to grow (Casson, 1990; Chow \& Fung, 1996; Reynolds, 1997). From another perspective, Acs (1992) argues that the concept of entrepreneurship - a term that has been derived from EO- is related to small businesses and enterprises. Despite the multiplicity of definitions that define the concept of entrepreneurship and EO, three specific components determine this approach accurately to the society for which the term is specified. These components as cited by Kostova (1997) and Scott (1995) are consistent organising on the part of the government, people's actual awareness and community's standards. In connection with the above components, Busenitz et al. (2000) investigate these components in details and the study's conclusion was that consistent organising by the government should include regulations and legislations that support the growth of small businesses, reduce potential risks to which small businesses might be exposed, and enable those businesses to access main sources. Continually, the people's actual awareness component should include essential information and basic skills that encourage and support individuals to start their own small business, which is reflected in providing information resources and certain skills training (Busenitz et al., 2000). Lastly, the community's standards component should involve a method that measures the ability of the local society to adopt innovations and new methods, especially those innovations and methods that refer to regenerated innovation orientation (Busenitz et al., 2000).

Even though there is no particular definition of EO and entrepreneurship, there is almost an agreement that any definition of EO should include a determination of individuals' work, an organisation's mission and a sound environment (Lumpkin \& Dess, 2001). However, there is also a group of antecedent researchers in this field who emphasise that this thought should be based on three basic components and they are innovation in problem-solving, being proactive in implementing strategies and initiatives that help to obtain available resources, and the ability to take high-risk actions or decisions (Miller, 1983; Morris \& Paul, 1987; Covin \& Slevin, 1989). Cunningham and Lischeron (1991), furthermore, inspect various research schools to define the concept of EO or entrepreneurship. They mention, 1. the school which focuses on pioneer persons who are born with unique characteristics that distinguish themselves to start their own distinctive business, 2. the school which believes that EO or entrepreneurship focuses on the extent of the individual qualifying and his ability to absorb the essential skills that are useful in starting one's own business, 3. the school that centralised innovation among other factors to describe EO, 4. the school of administration which focuses on an organisation that has economical strengths and competitiveness, 5. leadership school that focuses on an individual's leadership abilities to spread EO all over the organisation, and finally they mention, 6. entrepreneurship school which combines a mix of previous concepts in which individuals can adopt innovative ideas that help to broaden various aspects of the market. Nevertheless, it can be argued that EO approach, in actual practice, began from the need to change in an innovative way that may solve problems or bring about better development through available resources in a competitive environment (Zahra, 1991). Therefore, any definition of EO includes certain dimensions that are consistent with any school the researcher belongs to, and this is what will be discussed below.

\subsection{Dimensions of Entrepreneurial Orientation}

In a definition presented by Miller (1983, p. 771) EO "is one that engages in product-market innovation, undertakes somewhat risky ventures and is first to come up with proactive innovations, beating competitors to the punch. A non-entrepreneurial firm is one that innovates very little, is highly risk averse and imitates the moves of competitors instead of leading the way." The definition has an obvious mission that EO or entrepreneurship is supposed to encourage internal change in the external environment and competition. Thus, researchers such as Stevenson et al. (1985) define EO and entrepreneurship as a company's ability to improve internal innovation process and to determine the level of complexity among the process of market decision making. In addition, Morris and Paul (1987, p. 251) define EO as "the propensity of a company's management to take a calculated risk, to be innovative and to demonstrate pro-activeness in their approach to strategic decision making". Lumpkin \& Dess (1996) urges that EO is an advanced step to which an organisation's strategies to adopt pioneer ideas and new technologies are critically 
forced when market competition is high. Each definition has different dimensions of EO based on the author's experiences and context.

Authors like Morris and Paul (1987) determine EO based on three dimensions: 1. innovation linked to new products and services that have real values to consumers, 2. take the risk of decisive strategic decisions, and 3. pro-activeness based on market changes. These three dimensions are widely addressed in literature among small and newly emerged entities when owners and managers are meant to take full responsibility and full authorities to take critical decisions. These three dimensions also are being applied among large entities, but in less focus compared to other small and medium enterprises. Ultimately, organisations have a higher chance to overcome and grow whenever these three dimensions are actively applied even with economic and market fluctuations (Wiklund, 1998). Thus, EO has become a standard to measure an organisation's sustainability in the market (Miles et al., 2004). However, many entrepreneurs usually depend on their assumptions and that requires them to keep developing intuitive thinking skills (Chaston, 2009). Furthermore, Lyon et al. (2000) designate norms that can measure EO via: 1. understanding the organisation's administrative perceptions through the organisation's strategies, its hierarchy, process of critical decisions making and overall performance, 2. An organisation's behaviours and activities through its strategic plan activation and effective actions as well as response to external changes and threats, and 3. determination of main important resources that enable the organisation to sustain itself and grow in the market.

EO, from another perspective, can be measured through a different model. Lumpkin and Dess (1996) present a model that can determine EO effectiveness among organisations through five dimensions: 1. innovativeness that is not limited to innovating new products and services but includes new methods and procedures that create an innovation environment among organisations, 2. personal institutional level of autonomy which means that the organisation is capable of acting and implementing its strategies without any external interference, 3. risk-taking in business that has more value and revenues, 4 . pro-activeness in dealing with market changes and competitions, and 5. competitive aggressiveness and competitive capability to ensure sustainability in the market. Afterwards, Ahmed and Hoffmann (2008) have broadened the EO concept to involve more factors that refer to different aspects: 1. precisely define entrepreneurship concept internationally to comprise regular and legal framework, market conditions, funding, the ability to gain resources, research and development, technical development, entrepreneurial skills and adequacies and local culture, 2. individual and group performances, which include organisational growth, growth in number of employees and revenues growth, 3. and expected results of conducting a real entrepreneurial business and its effectiveness among the local society, which also includes number of jobs that have been created through those new entrepreneurial businesses, participating ratio of economic growth, participating ratio of reducing poverty among the local society and regulating non-governmental sectors.

\subsection{Governmental Organisations' Performance Measurement}

There is quite a large body of literature that indicates organisations' performance in general and varies based on an organisation's nature and type, whether it is governmental, semi-governmental or commercial. This research focuses on governmental organisations and the research population is specified accordingly. Because this type of organisations are not meant for profit at any level, performance measurements are varied and somehow difficult to assess (Brown \& Pyers, 1988). Some authors like Reid (1989) measure governmental organisations' performance through a direct beneficiary survey which is one of the main kinds of measurements seeking beneficiaries' opinions of their satisfaction about government departments' services. In another hand, Greene (2009) urges that most government performance measurable instruments would not be sustained for a long time due to frequent changes in local government's rules and regulations. To that extent, literature is full of different government performance measurement and cannot adopt all of them. Thus, the focus in this research is on three dimensions only. These dimensions are: 1. stimulating effective work environment which concerns the organisation's ability to improve the internal work environment and create an attractive environment that enables all employees to do their work without any disruption or feeling that they are in an aggressive competition, 2. ability to achieve the organisation's goals and objectives, which is the most important factor to measure the organisation's performance, especially among government sectors where increased revenue is usually not one of their main goals but instilling their vision and mission in their employees is a major concern, and, 3. ability for self-development which is one of most critical factors that government sectors use to measure training and development programme outcomes.

When the talk is about the internal environment, the internal culture must be addressed. This culture is acquired and promoted over time, and there is quite a large number of studies and research works on the importance of organisational culture and how the work environment can be shaped. Schein (1985), Hofstede et al. (1990) and Martin $(1992,2002)$ present reliable results of how positive internal organisational culture can create a good internal 
work environment and at the end improve the organisation's general performance. Furthermore, Ahmed (1998) confirms that whenever the internal work environment is stimulated, creativity and innovativeness will be higher and better. Continually, the ability to achieve an organisation's goals and objectives is a basic method to measure the organisation's performance, and any instrument should consider this factor (Carver \& Scheier, 1998). Meanwhile, one of the most important factors that ensure goal achievement is the individuals' ability to clearly understand the organisation's goals and the appropriate time for presenting these goals (Gollwitzer, 1999). A study conducted by Gollwitzer and Sheeran (2006) analysed 94 previous research works about individuals' ability to achieve their own goals and their organisation's goals; they found that definition of goals by itself is not sufficient to ensure goal achievement and there must be initiatives and intentions which reflect these goals. Recently, Ayers (2015) suggested linking organisational goals to individual goals to create potential achievement. Moreover, the ability for self-development has become an essential factor in developing overall organisation performance and creating tangible values of training courses (Van-der Merwe \& Malan, 2013). Without internal motivation for individual self-development, most training courses would not be beneficial.

\subsection{Implementation of Entrepreneurial Orientation on an Organisation's Performance}

In a research conducted by Miller (1983), he finds that there is quite an obvious impact among organisations that adopt EO in individual leadership, the internal environment, organisation's strategic implementation and organisational hierarchy in various effects. Similarly, Morris and Paul (1987) investigate the relationship between marketing orientation and EO, and they find that, whenever there are good understanding and implantation of entrepreneurial origination, the organisation will be sensitive to the market and become more marketing-orientated. Honestly, it is an inevitable result because there are quite a lot of similarities between marketing orientation dimensions and EO dimensions. Continually, Lumpkin and Dees (1996) investigate the impact of EO adaptation on an organisation's general performance, and they find that there are particular dimensions of EO that have an impact on an organisation's performance at various levels such as responding or pro-activeness against any change that happens in the market. Although their aim was to improve the dimensions of EO among organisations in general, their study proves each dimension has an uneven impact which depends on the organisation's hierarchy, its strategic reasonability and effectiveness of leadership.

Hla: Innovation has a significant impact on the internal environment's effectiveness.

$H 1 b$ : Innovation has a significant impact on the ability to achieve the organisation's goals.

HIc: Innovation has a significant impact on individual self-development.

The effectiveness of EO within the organisation has been debated widely. Lyon et al. (2000) say that the fundamental impact of EO can be clearly indicated on organisational ability to build an effective strategy and process of decision-making. Yusuf (2002) also investigates the implementation of EO among industrial and commercial organisations and to what extent these organisations can measure unstable, unpredictable and changeable environment, and he proves that an organisation with an effective EO is more able to predict and measure an unstable environment which can be found among industrial organisations more than commercial ones. To that extent, and to the importance of EO, AACSB has included EO and activities that support EO as one of the assessment measurements to gain institutional accreditation (The Association to Advance Collage Schools of Business [AACSB International], 2003). Lately, Hazeldine and Miles (2007) provide a set of standards that measure EO level among business schools, particularly among deans of business schools. Those standards have been modified by AACSB, which specifically determines innovation within the school's education and research activities along with autonomy at the level of school management (AACSB International, 2013). Hazeldine and Miles (2007) found and tested those standards among Western business schools, which have two attributes. 1. Mostly, these schools are attached to governmental or semi-governmental universities. 2. The standers measure EO among people who are supposed to be up to that mentality of EO. Thus, the study is not sufficient to include all governmental sectors.

$H 2 a$ : Autonomy has a significant impact on internal environment effectiveness.

$H 2 b$ : Autonomy has a significant impact on the ability to achieve an organisation's goals.

$H 2 c$ : Autonomy has a significant impact on individual self-development.

One of the most interesting studies that measure the impact of EO on general performance of public higher education institutes was conducted by Felgueiria and Rodrigues (2012), and they found a significant relationships between EO and marketing orientation proving that, when EO is at a high level, market orientation also that that high and similar impact. Another study conducted by Abou-Warda (2015) investigated the existence of EO among governmental, private, combined and international business schools in Egypt. It reveals that each type of schools has a particular 
explanation of EO, but private schools have more liberty to practice EO effectively. Also, Van-der Merwe and Malan (2013) examine five dimensions of EO impact - innovation, autonomy, risk-taking, pro-activeness and competitive aggressiveness - on ability to achieve strategic plans at governmental secondary schools, and the results of the study expose a strong and significant positive relationship between what can be called "EO mentality" of school managers and ability to achieve expressive effect of strategic plan except for risk-taking, which has no explanation among this type of schools. This study is supported by another study proving that EO has a strong impact on the general performance of government schools in New Jersey except for risk-taking (Phelan et al., 2013).

$H 3 a$ : Risk-taking has a significant impact on internal environment effectiveness.

$H 3 b$ : Risk-taking has a significant impact on the ability to achieve the organisation's goals.

$H 3 c$ : Risk-taking has a significant impact on individual self-development.

H4a: Proactivness has a significant impact on internal environment effectiveness.

$H 4 b$ : Proactiveness has a significant impact on the ability to achieve an organisation's goals.

$H 4 c$ : Proactiveness has a significant impact on individual self-development.

Based on the reviewed literature, a conceptual model is being developed in figure 1 to facilitate and visualise the research problem and identify main variables, which are undertaken in this study. The model also simplified the examination and analysis techniques that will be applied.

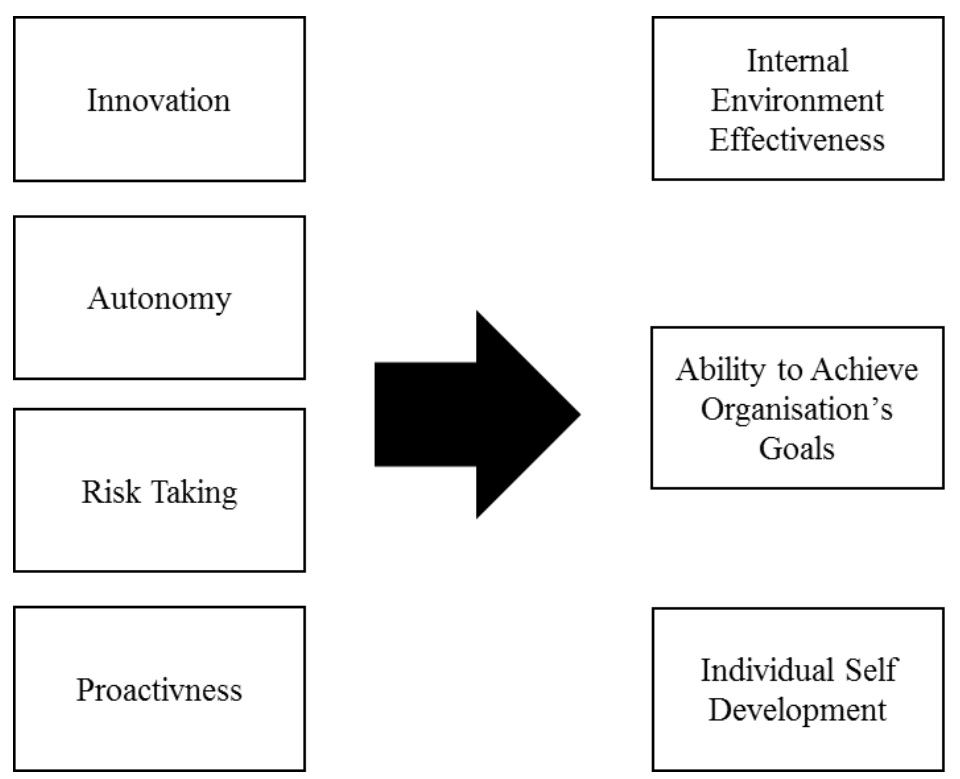

Figure 1. Entrepreneurial orientation impact on organisation's performance

The first factor is EO, which consists of four variables that determine the existence of EO in an organisation. These variables are as follows. 1. Innovation: This is reflected in commercial organisations in the volume of products or services developed based on the creative manner or innovative patent. However, the governmental sector has different meanings of innovation that consider new or developed services that increase beneficiaries' satisfaction and eliminate any disturbance. 2. Autonomy: In the commercial sector, autonomy is about the level of individual practice and level of independence of decision making that has a direct impact on organisational performance administratively and financially. In the governmental sector, autonomy is about the level of authorisation deputised to employees in order to take responsibility and act directly. It should be taken into consideration that financial responsibility is not accounted in this research because many government employees have limited financial authorisation. 3. Risk-taking: Commercially, it means to take risks and accept the consequences associated with any decision, especially financial decisions. In the government sector, financial risk is mostly avoided. Thus, this dimension will be measured in this research through the percentage of successful and failed services provided. 4. Pro-activeness: This dimension is described among the commercial sector when a company predicts changes in the market, act accordingly and seek to be the leader instead of following others or imitating them. In the governmental 
sector, competition has less effect in a manner of controlling the market. This dimension will be measured in the governmental sector through the level of responding on the part of government organisations based on beneficiaries' needs and requirements and beneficiaries' satisfaction about services.

On the other hand, the organisation's performance is the second factor and consists of three variables. The variables measure the extent of change in organisational performance in general. The variables are determined based on actual work and the nature of public and governmental entities, which mostly aim to improve services provided. These variables are as follows. 1. Internal environmental effectiveness, which is represented by the organisation's ability to improve internal workplace and create an attractive environment that helps the employee to act and perform smoothly without any disturbance or aggressive competitiveness. 2. Ability to achieve organisation's goals, which is the most important target, especially in those public organisations where financial goals are not considered. Alternatively, public and governmental organisations usually spread their vision and mission widely and among their employees to allow everyone understand clearly what the organisation is approaching and keen to achieve. 3 . Individual self-development. Basically this method of measurement is used extensively by governmental organisations to discover what kind of employees' characteristics might have the ability to develop himself. Accordingly, the research's conceptual model represents the four variables of EO which were developed by Van der Merwe and Malan (2013) knowing that innovation, risk-taking and pro-activeness are adopted from Morris and Paul (1989) and have been used widely in the commercial score.

\section{Research Methodology}

\subsection{Research Problem}

Since the start of reviewing most of the relevant studies about EO theoretical or practical researches, the researcher has not found any results related to the governmental or public sector. In particular, there is no previous study or research that articulates whether EO has any impact on individual or group performance in the governmental sector. Knowing that EO has been widely applied in the commercial sector from different aspects, the organisation's performance mostly. As an example of those research, which are used extensively, the reader can refer to Miles and Arnold (1991); Chaston (1997); Davis et al. (1991); Dess et al. (1997); Kohli and Jaworski (1990); Matthews and Scott (1995); Hills et al. (2008); Kocak and Abimbola (2009) and Martin (2009). Accordingly, there is a knowledge gap in defining EO in the governmental sector, especially when many of the researchers mentioned the importance of implanting this concept to improve general performance, at least. However, there is no particular reliable study that can be relied on and trusted that measures level of EO among governmental organisations. From the author's point of view, that purpose was enough to proceed with this research and to measure the impact of EO on governmental organisations' performance.

\subsection{Aim and Objective of This Research}

The aim of this research is to determine whether EO applied among public and governmental organisation, and if so, the next step is to measure EO's impact on the general performance of public and governmental organisations. In order to improve research processes, the aim of this research has been broken into five objectives:

- To verify the validity and reliability of current EO instrument among public and governmental organisations.

- To verify the validity and reliability of current organisational performance instrument among public and governmental organisations.

- To determine whether the EO concept is applicable among public and governmental organisations.

- To determine the impact of adopting EO among public and governmental organisations on organisations' general performance.

- To fill the knowledge gap of EO and understand its implications among public and governmental organisations.

\subsection{Research Approach}

This research is built based on the positivism research philosophy, which depends on previous assumptions and contains valuable information on the subject. This information might be part of the research or can be turned to new assumptions in future (Lee, 1999). As mentioned above, EO and organisation's performance are elucidated widely among commercial sectors. However, EO as an adaptable concept and practice and has not been utilised in public and governmental organisations, and the EO relationship has not been used in organisational performance. Thus, positivism philosophy is applied in this research to examine relationships between the two variables. Continually, the research is designed to be a descriptive research built upon ambiguous previous knowledge of the research topic 
(Churchill, 1999; Lancaster, 2005; Saunders et al., 2012). Moreover, a qualitative approach is used to determine relationships between variables and to test several hypotheses (Mangal \& Mangal, 2013).

\subsection{Measurement}

Based on previous studies, two models can measure EO. The first model is presented by Morris and Paul (1987) and consists of three dimensions: innovation, risk-taking and pro-activeness. The second model is developed by Lumpkin and Dess (1996) and consists of the three dimensions plus autonomy and competitive aggressiveness. The later model was used widely, for example, Naldi et al. (2007), Lotz (2009), and Yildirim and Sygin (2011). Van der Merwe and Malan (2013) developed items of the second model as a complete instrument of measurement. In this research, the second model is adopted except competitive aggressiveness, which has no obvious role in public and governmental sectors. On the other hand, organisation's performance measurement focuses on three dimensions which are internal environmental effectiveness as presented by Ahmed (1998), ability to achieve organisation's goals as mentioned by Carver and Scheier (1998) and individual self-development as presented by Van der Merwe and Malan (2013). The latter authors have developed instruments and items for the three variables, which is adopted in this research.

To test the proposed hypotheses and determine the relationships of all variables, items have been translated into Arabic and a well-designed questionnaire is developed homogeneously. Respondents should then indicate their level of agreement with all items based on the Likert scale which starts from completely disagree to completely agree. The questionnaire is then sent to five specialist academics to maintain internal validity. There were view changes on items' statement to clarify any misunderstanding but not affecting the meaning of items. Afterwards, the questionnaire has been tested among fifteen respondents picked up from the population of the research. There were also minor changes on the statement of the items. The questionnaire was approved.

\subsection{Research Population and Sample}

The population was determined to be governmental organisations in Tabuk city, Saudi Arabia. Most of these organisations are branches with their headquarters in the capital city, Riyadh. Unfortunately, there is no dependable list of governmental organisations in Tabuk. However, there are several websites providing free services that list most of the governmental organisations in Tabuk. Each website is different from the others and has its specific concerns. From those websites, a list of governmental organisations was obtained in personal efforts that consist mainly of landlines and addresses. The list contains 47 public and governmental organisations in Tabuk and all of them are concerned with the research population. The sample was determined to include the entire research population. When approaching these organisations, the number of responses is specified according to the number of head employees of each organisation. There is only one condition for the respondent candidate, he or she must be a head of a department, manager or chief executive with supervision tasks and report to someone who has a higher position than him or her. In other words, the candidate must be a head and subordinate both at the same time.

\subsection{Data Collection}

A well-designed and tested questionnaire has been distributed among the 47 organisations in Tabuk city. The questionnaire was distributed in hard copy format and manually. Five hundred and thirty copies of the questionnaire were handed out, asking respondents to answer each question fairly and voluntary. Two hundred and forty-two copies were returned, a response rate of $45.6 \%$. Only 156 completed questionnaires were found and included in the analysis process.

\section{Analysis and Results}

\subsection{Statistical Analysis Tools and Demographics Data}

Three stages of statistical analysis were applied in this research. First, coefficient reliability was calculated using Cronbach's Alpha coefficient, which applied upon each set of variables. Exploratory factor analysis was followed to make sure that measuring instruments are reliable and applicable among Saudi governmental sectors; these items were translated from English to Arabic. The last stage is to apply the multiple leaner regression. At this stage, hypotheses and variable relationships are tested accordingly using IBM SPSS Statistics 23.

The total number of approved questionnaires was 156; $91 \%$ of them were male and $9 \%$ female. Most of the respondents' age ranged between 36 to 45 years old with a rate of $75.6 \%$ of total respondents; $16 \%$ of them ranged between 26 and 35 years old and $8.4 \%$ between the ages of 46 and 55 years old. Regarding respondents' education level, most of them are graduates with a rate of $67.9 \% ; 19.9 \%$ are at the level of high school, and $12.2 \%$ of the 
respondents are at the level of diploma. Finally, $91 \%$ of all respondents are general managers and only $9 \%$ of them are department managers.

\subsection{Reliability Coefficient}

Reliability analysis includes four variables for EO. Innovation variable has been measured 11 times. The other variables, which are autonomy, risk-taking and pro-activeness, were measured by 5 items for each variable. Reliability coefficients were $.885 ; .933 ; .904$ and .852 , respectively. On the other hand, organisation's performance has three variables - internal environment effectiveness, which has been measured by 9 times, ability to achieve organisation's goals, which has been measured 5 items, and individual self-development, which has been measured 4 items. Reliability coefficients were $0.841,0.857$ and 0.869 , respectively. Considering these coefficients as good value and accepted in the social sciences. George \& Mallery (2003) mention that any value above or equal to .90 is excellent, above or equal to .80 is good and above or equal to .70 is acceptable. However, any variable which can be measured by 4 or more items and score .75 , at least, is accepted in the social sciences, and that includes business studies (Pettigrew, 1979).

\subsection{Exploratory Factor Analysis}

It is important to perform exploratory factor analysis (EFA) to know the interconnection between different factors and to determine which items have more loading than others do in each factor (Hair et al., 2006). In addition, these items have been translated from English to Arabic and sometimes measuring instruments might not be applicable to another context. For that reason, EFA was performed according to Field's (2009) way of running this type of analysis. Moreover, this type of analysis was run to achieve one of the research's objectives, which is to verify the validity and reliability of the current EO instrument among public and governmental organisations and current organisational performance instrument among public and governmental organisations. Before implementing EFA, the sample size must be justified where sample size has a significant role in interpreting EFA result. Kass and Tinsley (1979) mention that sample must contain 5 to 10 participants for each question with a conduction not to exceeding 300 participants, and Tabachnick and Fidell (2007) agree. However, Guadagnoli and Velicer (1988) say that if the sample size is below 300 participants, it is possible to review the EFA table, and if there are four loads equal to or above 0.60 for each factor, then the model can be accepted and has a good reliability with the condition that the sample size be not less than 100 participants, and this condition is met in this research as shown in tables 1 and 2 . 
Table 1. Rotated factor matrix "entrepreneurial orientation"

\begin{tabular}{|c|c|c|c|c|}
\hline \multirow[b]{2}{*}{ Items } & \multicolumn{3}{|c|}{ Components } & \multirow[b]{2}{*}{$\begin{array}{c}\text { Factor } 4 \\
\text { Proactivness }\end{array}$} \\
\hline & $\begin{array}{c}\text { Factor } 1 \\
\text { Innovation }\end{array}$ & $\begin{array}{c}\text { Factor } 2 \\
\text { Autonomy }\end{array}$ & $\begin{array}{c}\text { Factor } 3 \\
\text { Risk Taking }\end{array}$ & \\
\hline Innovation 01 & .880 & .025 & .006 & -.069 \\
\hline Innovation 02 & .772 & .027 & .046 & -.018 \\
\hline Innovation 03 & .729 & -.149 & -.007 & .397 \\
\hline Innovation 09 & .700 & .149 & .177 & -.023 \\
\hline Innovation 11 & .698 & .014 & .227 & .197 \\
\hline Innovation 04 & .690 & .225 & -.056 & .320 \\
\hline Innovation 08 & .592 & .489 & -.094 & .218 \\
\hline Innovation 05 & .553 & .139 & .039 & .123 \\
\hline Innovation 06 & .522 & .383 & .108 & .314 \\
\hline Autonomy 01 & .007 & .917 & .056 & -.015 \\
\hline Autonomy 03 & .177 & .900 & -.043 & .133 \\
\hline Autonomy 05 & .177 & .884 & -.016 & -.083 \\
\hline Autonomy 02 & .021 & .883 & .114 & .088 \\
\hline Autonomy 04 & .015 & .827 & .137 & .326 \\
\hline Risk Taking 03 & .003 & .013 & .864 & .210 \\
\hline Risk Taking 02 & -.011 & -.152 & .856 & .172 \\
\hline Risk Taking 01 & .130 & -.010 & .814 & .300 \\
\hline Risk Taking 05 & .143 & .195 & .765 & .149 \\
\hline Risk Taking 04 & .058 & .322 & .735 & .105 \\
\hline Innovation 10 & .357 & -.091 & .382 & -.080 \\
\hline Proactivness 03 & .121 & .020 & .404 & .773 \\
\hline Proactivness 02 & .147 & .150 & .015 & .746 \\
\hline Proactivness 05 & .061 & .133 & .418 & .686 \\
\hline Proactivness 04 & .058 & .096 & .462 & .674 \\
\hline Proactivness 01 & .239 & .485 & .154 & .582 \\
\hline Innovation 07 & .509 & -.027 & .108 & .576 \\
\hline Eigenvalues & 4.87 & 4.85 & 4.14 & 3.55 \\
\hline$\%$ of variance & 18.74 & 18.66 & 15.95 & 13.68 \\
\hline$\alpha$ & .885 & .933 & .904 & .852 \\
\hline
\end{tabular}

At the first model of EFA, which contains variables of EO with 26 items, the first step is to make sure that variable measurement is valid through Matrix of Bivariate Correlation (MBC) and check Multicollinearity, which must not to exceed 0.90 and be above 0.60 (Field, 2009). This is already met in the model. The second step is to make sure of sufficient sample size using Kaiser-Meyer-Olkin (KMO). This measurement must be above 0.50 and can be accepted (Kaiser, 1974). In this model, KMO is 0.754 which is good and data is accepted. The last step of checking is Bartlett's measurement, which measures null hypotheses. In this model, $\mathrm{X}^{2}$ (352) is equal to $3853.597 p<.001$, which indicates that there is a significant relationship between the variables. Four factors have been determined in EFA with a value above 1 . According to KMO measurement, these four factors present $67 \%$ of total variation. As EO factors are assigned in advance and have been examined widely in various private sectors, the four factors' new loading are shown in table 1. According to the EFA, the first factor is innovation, which represents the level of innovation in the organisation and can be measured by 10 items which load $\geq .40$. Previously, innovation has been measured by 11 items where an item (innovation 10) is removed due to unaccepted loading. In addition, the autonomy factor, which represents leave of decision independence in the organisation was measured by 7 items based on EFA results. Items "innovation 08 and pro-activeness 01 " were added to these factors due to high load. Risk-taking was measured by 8 items, and five of them were originally part of this factor plus 3 items "pro-activeness 03 , pro-activeness 04 and pro-activeness 05 ", which have a significant load to measure risk-taking factor. Finally, it can be noticed that the pro-activeness factor can be measured by 6 items, five of which are originally part of this factor plus "innovation 07 ". Appendix 1 shows a new allocation of items after EFA. 
Table 2. Rotated factor matrix "organisation's performance"

\begin{tabular}{|c|c|c|c|}
\hline \multirow[b]{2}{*}{ Items } & \multicolumn{3}{|c|}{ Components } \\
\hline & $\begin{array}{c}\text { Factor 1 } \\
\text { Internal Environment } \\
\text { Effectives }\end{array}$ & $\begin{array}{c}\text { Factor } 2 \\
\text { Ability to Achieve } \\
\text { Organisation's Goals }\end{array}$ & $\begin{array}{c}\text { Factor } 3 \\
\text { Individual Self } \\
\text { Development }\end{array}$ \\
\hline Environment 01 & .821 & -.144 & .269 \\
\hline Environment 03 & .785 & .087 & .292 \\
\hline Goals 04 & .755 & .379 & .006 \\
\hline Goals 02 & .750 & .018 & .179 \\
\hline Goals 05 & .740 & .154 & .293 \\
\hline Goals 01 & .713 & .393 & .225 \\
\hline Goals 03 & .661 & .195 & .146 \\
\hline Environment 04 & .631 & .365 & .263 \\
\hline Development 03 & .277 & .852 & .043 \\
\hline Development 02 & .065 & .814 & -.015 \\
\hline Development 04 & .045 & .809 & .016 \\
\hline Development 01 & .173 & .809 & .145 \\
\hline Environment 05 & -.022 & .102 & .724 \\
\hline Environment 02 & .373 & .271 & .670 \\
\hline Environment 09 & .426 & -.005 & .664 \\
\hline Environment 08 & .144 & .539 & 638 \\
\hline Environment 06 & .287 & -.014 & .480 \\
\hline Environment 07 & .247 & -.124 & .450 \\
\hline Eigenvalues & 4.90 & 3.60 & 2.69 \\
\hline$\%$ of variance & 27.27 & 20.05 & 14.96 \\
\hline$\alpha$ & .857 & .869 & .841 \\
\hline
\end{tabular}

The second model of EFA consists of organisation's performance variables with 18 items. As mentioned above, there is no significant issue in Multicollinearity where all correlations are less than 0.90 and above 0.60 , and KMO is 0.834 which is good value and model is accepted. Bartlett's measurement $X^{2}$ (153) equals $1866.619 p<.001$, which indicate that there are significant relationships between variables. Three factors were determined in EFA with a value above 1 based on Kaiser which considers $62 \%$ of data variation. These factors are shown in table 2 . According to the EFA, the first factor is "environment", which represents internal environment effectiveness and has a considerable issue in this analysis. This factor was measured by 6 items out of 9 original items. The other three items were loaded with other factors. The second factor (goals) which represents the organisation's ability to achieve its goals is measured by 9 items that have a load $\geq .40$. Three more times were added to this factor. Those are "environment 01 , environment 03 and environment 09 " which proves their loading in the goals factor. Finally, the "development" factor, which represents employees' ability to develop themselves, is measured by 5 items plus item the "environment 08 ". Appendix 2 shows a new allocation of items after EFA.

\subsection{Multiple Leaner Regression (MLR)}

The main reason behind this research is to know the impact of EO, and those are independent variables in an organisation's performance and dependent variables. Thus, a multiple leaner regression was performed among three models. Each model consists of the four independent variables against one of the dependent variables. The result of multiple leaner regression is presented in tables 3 to 5 . 
Table 3. Multiple regression results: influence of entrepreneurial orientation on internal environment effectiveness

\begin{tabular}{|l|c|c|c|}
\hline \multirow{2}{*}{ Model } & \multicolumn{2}{|c|}{ Unstandardized Coefficients } & Standardized Coefficients \\
\hline Constant & $\boldsymbol{B}$ & $\boldsymbol{S E} \boldsymbol{B}$ & $\boldsymbol{\beta}$ \\
\hline Innovation & 1.018 & 0.673 & $0.911^{* * *}$ \\
\hline Autonomy & 0.528 & 0.018 & $0.110^{* * *}$ \\
\hline Risk Taking & 0.081 & 0.022 & 0.053 \\
\hline Proactivness & 0.026 & 0.019 & -0.056 \\
\hline
\end{tabular}

Note: $\mathrm{R}^{2}=0.91(* p<.05 ; * * p<.01 ; * * * p<.001)$

The first model, as shown in table 3, measures and determines the relationship between the internal environment's effectiveness as a dependent variable and EO variables. $91 \%$ of the variation (which is a significant percentage and the model is accepted) in the internal environment's effectiveness variable is explained by four variables of EO. This value is accepted accordingly to proceed with the next step of the analysis. The model shows a significant positive relationship between the internal environment's effectiveness and two variables of EO. Those are innovation $(0.528$, $p<.001)$ and autonomy $(0.081, p<.001)$. However, there is no significant relationship between the internal environment's effectiveness and the other two variables of EO. Those are risk-taking $(0.026, p>.05)$ and pro-activeness $(-0.042, p>.05)$. Therefore, hypothesis $\mathrm{Hla}$ that stated a significant relationship between innovation and internal environment's effectiveness and $H 2 a$ which pretend a significant relationship between autonomy and internal environment's effectiveness are accepted. The two hypotheses $H 3 a$ and $H 4 a$ are rejected.

Table 4. Multiple regression results: influence of entrepreneurial orientation on ability to achieve organisation's goals

\begin{tabular}{|l|c|c|c|}
\hline \multirow{2}{*}{ Model } & \multicolumn{2}{|c|}{ Unstandardized Coefficients } & $\begin{array}{c}\text { Standardized } \\
\text { Coefficients }\end{array}$ \\
\hline Constant & $\boldsymbol{B}$ & $\boldsymbol{S E} \boldsymbol{B}$ & $\boldsymbol{\beta}$ \\
\hline Innovation & 8.939 & 2.269 & -0.062 \\
\hline Autonomy & -0.062 & 0.061 & $0.397 * *$ \\
\hline Risk Taking & 0.500 & 0.073 & 0.110 \\
\hline Proactivness & 0.094 & 0.063 & $0.484 * * *$ \\
\hline
\end{tabular}

Note: $\mathrm{R}^{2}=0.91(* p<.05 ; * * p<.01 ; * * * p<.001)$

The second model as shown in table 4 indicates the relationship between the ability to achieve the organisation's goals and four variables of EO. Sixty-three percent of the variation in the dependent variable, ability to achieve organisation's goals, is explained by the four variables of EO. This variation is significant and the model of regression is accepted. MLR in the second model also indicates a positive significant relationship between the ability to achieve organisation's goals as a dependent variable and autonomy $(0.500, p<.001)$ and pro-activeness $(0.634$, $p<.001)$ as independent variables of EO. However, there is no significant relationship between the ability to achieve organisation's goals and the remaining two variables of EO which are innovation $(-0.062, p>.05)$ and risk-taking (0.094, $p>$.05). Thus, hypotheses $H 1 b$ and $H 4 b$ are accepted and $H 2 b$ and $H 3 b$ are rejected.

Table 5. Multiple regression results: influence of entrepreneurial orientation on individual self development

\begin{tabular}{|l|c|c|c|}
\hline \multirow{2}{*}{ Model } & \multicolumn{2}{|c|}{ Unstandardized Coefficients } & Standardized Coefficients \\
\hline Constant & $\boldsymbol{B}$ & $\boldsymbol{S E} \boldsymbol{B}$ & $\boldsymbol{\beta}$ \\
\hline Innovation & 12.352 & 1.990 & -0.160 \\
\hline Autonomy & -0.103 & 0.053 & 0.124 \\
\hline Risk Taking & 0.101 & 0.064 & $0.678^{* * *}$ \\
\hline Proactivness & 0.370 & 0.055 & -0.188 \\
\hline $\mathrm{R}^{2}=0.91(* p<.05 ; * * p<.01 ; * * * p<.001)$ & 0.100 & \\
\hline
\end{tabular}

Note: $\mathrm{R}^{2}=0.91(* p<.05 ; * * p<.01 ; * * * p<.001)$ 
The third model as shown in table 5 elucidates a significant percentage that only $39 \%$ of the variation in individual self-development, which is the dependent variable, is explained by independent variables (EO variables). The results show a significant positive relationship between risk-taking as an independent variable and individual self-development with a value $(0.370, p<.0010)$. The remaining three independent variables of EO are not significant. Thus, $H 3 c$ is the only hypothesis that is accepted. Others- $H 1 c, H 2 c$ and $\mathrm{H} 4 \mathrm{c}$-are rejected.

\section{Findings and Discussion}

Through all stages of the research, there are several findings that can be highlighted about EO among public and government organisations along with what can be changed in innovation and autonomy, which are related to work style, or the risk-taking of adopting and implementing new ideas and pro-activeness, which are related to services provided. All of these variables have a particular direct or indirect impact on organisations' performance. One the most interesting findings of this research is that EO variables themselves, which are represented by Lumpkin and Dess (1996), have a wide implication among commercial sectors that differ more than governmental sectors. These variables are subjected to accurate interpretation among governmental and public sectors that have been discovered through EFA. The most important variable in the process of converting to EO in the governmental and public sector is innovation in providing developed facilities and services that help beneficiaries to accomplish their requirements in a shorter time. Moreover, level of autonomy should be considered as well to allow employees do their job faster. However, risk-taking and pro-activeness have less value in the process of converting to EO among governmental and public sectors.

Mainly, there are three variables that have a significant role in measuring government organisation's performance. Although the internal environment's effectiveness has a problematic issue in EFA, it has an expressive role in measuring other variables. EFA shows that a part of this variable's items is considered within the other two variables due to the importance of this variable and to be included in any measurable instrument of the organisation's performance. Furthermore, stimulating the internal environment's effectiveness can enhance the level of innovation and creativity where this result is compatible with Ahmed (1998) and Martin (1992; 2002). Thus, it is very important to include the internal environment's effectiveness in this research and others as suggested. Achieving organisation's goals variable is the most powerful factor and carries the highest weight in measuring an organisation' performance. That result is agreed to Carver and Scheier's (1998) results. According to them, the true measurement of organisation's performance must consist of individual ability to achieve organisation's goals. Finally, EFA shows that individual self-development variable also has a role in measuring the organisation's performance by measuring individuals' skills and capabilities. In general, the three variables overlap in between each other, and each variable has an indirect or direct impact like the internal environment's effectiveness role among individuals' skills leverage.

Obviously, public or governmental sectors have a different interpretation of innovation, as this variable is limited to the kind of service that might add value. Innovation in governmental organisations as defined by Mulgan $(2007,6)$ "is about new ideas that work at creating public value. The ideas have to be, at least, partly new (rather than an improvement); they have to be taken up (rather than just being good ideas), and they have to be useful". Indeed, the positive relationship between innovation as an important factor of EO and improving the internal environment's effectiveness has revealed the stunning fact that, when the innovation process is adopted and enhanced, the internal environment's effectiveness is stimulated as well. In return, when the internal environment is enhanced, innovation practice prevail widely in the organisation. This result is similar to what Lyon et al. (2000) found in their study and partially similar to Van-der Merwe and Malan's (2013) findings. However, rooting innovation process in public and governmental sectors is a challenge. While this sector has hierarchical bureaucracies, adopting innovation practice needs a high level of delegation of authority to mid-level managers. As mentioned by Teofilovic (2002), one of the main barriers to adopting innovation in the government sector is leadership autonomy. On the other hand, the results of analysis expose no relationship between innovation and a government organisation's ability to achieve their goals on one hand and individual ability to improve themselves on the other. These results are contrary to previous literature. The reason might be that the ability to achieve an organisation's goals and individual improvement is a result of internal environment enhancement. Once the internal environment is enhanced and stimulated, the two factors follow. Again, the internal environment can be enhanced by adapting and enhancing the innovation level. Obviously, even when there is no significant relationship between innovation and ability to achieve an organisation's goals and individual ability to improve, the innovation process still can play a significant role to the two latter consequences.

Furthermore, autonomy has a significant relationship with the internal environment's effectiveness but less than innovation. Whenever autonomy level is high, the internal environment's effectiveness is simulated, and this 
increases the ability to achieve the organisation's goals. This outcome explains Ayers' (2015) results as he mentioned the importance of linking organisations' goals to individuals' goals. As a result of this research, an acceptable level of autonomy can help individuals to maintain their own goals which are linked to organisation's goals, and this will increase the ability to achieve them. On the contrary, autonomy has no relationship with individual self-development, and there is no specific explanation of this result. This outcome is different from what Abou-Warda (2015) revealed in her research, as a high level of autonomy supports individuals to improve themselves independently.

There is no relationship between risk-taking as one of the EO variables and the internal environment's effectiveness and ability to achieve the organisation's goals. These results are compatible with Van-der Merwe and Malan (2013) and Phelan (2013). The risk-taking factor is almost not existed in the governmental sector, given that organisations in this sector seek sustainability and do not take any decision that might affect working processes. However, the only relationship that can be noticed is between risk-taking and an individual's self-development. The reason behind this result might be the nature of individual decisions which can be taken independently and under the individual's responsibility. For example, an employee might take a resignation decision to commence further education. Thus, risk-taking is linked to individuals' decisions more than the organisation's level. Finally, the pro-activeness factor has a significant and direct relationship with the ability to achieve the organisation's goals. The result shows that when an organisation maintains and develop its services and facilities, the organisation's ability to achieve its goals will be raised. However, there is no relationship between pro-activeness as a factor of EO and the internal environment's effectiveness and individuals' ability to improve themselves. That can be explained as an organisation's services enhancement in a comprehensive approach of the whole organisation and not limited to individuals.

\section{Conclusion}

EO as a concept has several meanings at public or governmental sector in each elements. Innovation at this type of organisation is difficult to be achieved. They consider innovation as a process of improving internal work environment rather than adding value. Additionally, innovation never works alone, there has to be an average level of autonomy and responsibility to take the risk of own decisions. On the other hand, pro-activeness is in action when it comes to beneficiaries responses to current government services. However, most of government's actions classified within a reaction to feedback to which mostly not last for long.

\section{Research Limitations}

The main limitation is the research population, which does not cover a wide area. The population includes only governmental organisations in the city of Tabuk. Another limitation of this research is the sample size. In any region, it is known that the number of governmental organisations is varied and forked where including all the proposed samples is not possible. In this research, there are several conditions and specific criteria that must be met when choosing any possible participant. The criteria focus on responsibility and supervision tasks. Moreover, there is no reliable list that consists of all governmental organisations or branches in the region that allows the researcher to define an accurate population. The researcher depends on personal efforts and some websites which are interested in providing free services for the community to obtain a list of the most effective governmental organisations or branches in the city of Tabuk and estimates the number of employees applicable to the sample criteria in each institute. This limitation also leads to another one which is ineffective commutation channel such as emails where there is no way to obtain employees' emails. Data is collected manually and that takes up a lot of effort and time. Many of the distributed questionnaires were not returned, and most of the collected questionnaires are not valid for analysis due to a missing date. Thus, almost half of the returned questionnaires were not used.

\section{Further Research}

The results of this research are limited to a certain region. It might be computable or contrary to other researches that applied among different region or countries. The main recommendation for further research is to specify a certain governmental or public sector organisation, for example, all employees in the ministry of health or any other governmental organisation where they are located in one place mostly. Moreover, further research should include organisational outcomes such as measurable facts of performance. For example, governmental education institutions have outcomes different from any other sector. KPIs can somehow measure organisations' performance. Finally, not to forget that EO variables might differ from one organisation to another according to managerial hierarchy. 


\section{References}

AACSB International. (2003). Eligibility procedures and standards for business accreditation. Retrieved from http://www.aacsb.edu/

AACSB International. (2013). Eligibility procedures and standards for business accreditation. Retrieved from http://www.aacsb.edu/

Abou-Warda, S.H. (2015). Entrepreneurial rientation in business schools: A comparative study of higher education system in Egypt. International Journal of Education Management, 29(2), $192-212$. https://doi.org/10.1108/IJEM-11-2013-0165

Acs, Z.J. (1992). Small business economics: A global perspective. Challenge, 35(6), 38-44. https://doi.org/10.1080/05775132.1992.11471626

Ahmad, N., \& Hoffmann, A.N. (2008). A framework for addressing and measuring entrepreneurship. OECD Statistics Working Paper. Retrieved from http://www.oecd-ilibrary.org/

Ahmed, P.K. (1998). Culture and climate for innovation. European Journal of Innovation Management, 1(1), $30-43$. https://doi.org/10.1108/14601069810199131

Ayers, R.S. (2015). Aligning individual and organizational performance goal alignment in federal government agency performance appraisal programs. Public Personnel Management, 44(2), 169-191. https://doi.org/10.1177/0091026015575178

Brown. R.E., \& Pyers, J.B. (1988). Putting teeth into the efficiency and effectiveness of public service. Public Administration Review, 48(3), 735-742. Retrieved from http://www.jstor.org/stable/976253

Busenitz, L.W., Gomez, C., \& Spencer, J.W. (2000). Country institutional profiles: Unlocking entrepreneurial phenomena. Academy of Management Journal, 43(5), 994-1003. https://doi.org/10.5465/1556423

Carver, C.S., \& Scheier, M.F. (1998). On the self-regulation of behavior. Cambridge: University Press. https://doi.org/10.1017/CBO9781139174794

Casson, M. (1990). Enterprise and competitiveness. New York: Oxford University Press.

Chaston, I. (1997). How interaction between relationship and entrepreneurial marketing may affect organisation competencies in small UK manufacturing firms. Marketing Education Review, 7(3), 55-65. https://doi.org/10.1080/10528008.1997.11488607

Chaston, I. (2009). Entrepreneurs, intuition, and small-business performance. Journal of Centrum Cathedra, 2(1), 37-45. Retrieved from https://ssrn.com/abstract=1586431

Chow, C.K., \& Fung, M.K. (1996). Firm dynamics and Industrialization in the Chinese economy in transition: Implications for small business policy. Journal of Business Venturing, 11(6), 489-505. https://doi.org/10.1016/S0883-9026(96)00019-5

Churchill, G.A. (1999). Marketing research: Methodological foundations (7th ed.). Orlando: Dryden Press.

Covin, J.G., \& Slevin, D.P. (1989). Strategic management of small firms in hostile and benign environments. Strategic Management Journal, 10(1), 75-87. https://doi.org/10.1002/smj.4250100107

Cunningham, J.B., \& Lischeron, J. (1991). Defining entrepreneurship. Journal of Small Business Management, 29(1), 45-61.

Davis, D., Morris, M., \& Allen, J. (1991). Perceived environmental turbulence and its effect on selected entrepreneurship, marketing and organisational characteristics in industrial firms. Journal of the Academic of Marketing Science, 19(1), 43-51. https://doi.org/10.1177/009207039101900106

Dess, G., Lumpkin, G., \& Covin, J. (1997). Entrepreneurial strategy making and firm performance: Tests of contingency and configurational models. Strategic Management Journal, $18(1)$, 2-23. https://doi.org/10.1002/(SICI)1097-0266(199710)18:9<677::AID-SMJ905>3.0.CO;2-Q

Felgueira, T., \& Rodrigues, R.G. (2012). Entrepreneurial orientation, marketing orientation and performance of teachers and researchers in public higher educations. Public Policy and Administration, 11(4), 703-718. Retrieved from http://hdl.handle.net/10314/2521

Field, A. (2009). Discovering statistics using SPSS (3rd ed.). London: Sage Publications. 
George, D., \& Mallery, P. (2003). SPSS for windows step by step: A simple guide and reference (4th ed.). Boston: Allyn \& Bacon.

Gollwitzer, P.M. (1999). Implementation intentions: Strong effects of simple plans. American Psychologist, 54(7), 493-503. https://doi.org/10.1037/0003-066X.54.7.493

Gollwitzer, P.M., \& Sheeran, P. (2006). Implementation intentions and goal achievement: A meta-analysis of effects and processes. Advances in Experimental Social Psychology, 38, 69-119. https://doi.org/10.1016/S0065-2601(06)38002-1

Green, R. (2009). Measuring government performance to promote transparency. In C. Clark, \& D, Terry Veal (Eds.), Advance excellence and public trust in government (pp. 69-74). Lanham: Lexington Books.

Guadagnoli, E., \& Velicer, W.F. (1988). Relation of sample size to the stability of component patterns. Psychological Bulletin, 103(2), 265-275. https://doi.org/10.1037/0033-2909.103.2.265

Hair, J.F., Black, W.C., Babin, J.B., Anderson, R.E., \& Tatham, R.L. (2006). Multivariate data Analysis (6th ed.). Upper Saddle River, NJ: Pearson: Prentice Hall.

Hazeldine, M., \& Miles, M. (2007). Measuring entrepreneurship in business schools. Journal of Education for Business, 82(4), 234-240. https://doi.org/10.3200/JOEB.82.4.234-240

Hills, G.E., Hultman, C.M., \& Miles, M.P. (2008). The Evolution and development of entrepreneurial marketing. Journal of Small Business Management, 46(1), 99-112. https://doi.org/10.1111/j.1540-627X.2007.00234.X

Hofstede, G., Neuijen, B., Ohayv, D.D., \& Sanders, G. (1990). Measuring organisational culture: A qualitative and quantitative study across twenty cases. Administration Science Quarterly, 35(2), 286-316. https://doi.org/10.2307/2393392

Kaiser, H.F. (1974). An index of factorial simplicity. Psychometrikam, 39(1), 31-36. https://doi.org/10.1007/BF02291575

Kass, R.A., \& Tinsley, H.E.A. (1979). Factor analysis. Journal of Leisure Research, 11, 120-138. https://doi.org/10.1080/00222216.1979.11969385

Kocak, A., \& Abimbola, T. (2009). The effects of entrepreneurial marketing on born global performance. International Marketing Review, 26(4/5), 439-452. https://doi.org/10.1108/02651330910971977

Kohli A.K., \& Jaworski, B.J. (1990). Market orientation: The construct, research propositions, and managerial implications. Journal of Marketing, 54(2), 1-18. Retrieved from http://www.jstor.org/stable/1251866

Kostova, T. (1997). Country institutional profiles: Concept and measurement. Academy of Management Best Paper Proceedings, 180-189. https://doi.org/10.5465/ambpp.1997.4981338

Lancaster, G. (2005). Research methods in management: A concise introduction to research in management and business consultancy. Oxford: Elsevier Butterworth-Heinemann.

Lee, A.S. (1999). Rigor and relevance in MIS research: Beyond the approach of positivism alone. MIS Quarterly, 23(1), 29-34. https://doi.org/10.2307/249407

Lotz, H.M. (2009). An assessment of corporate entrepreneurship in agricultural businesses: An integrated framework. Unpublished PhD thesis, North-West University, Potchefstroom.

Lumpkin, G.T., \& Dess, G.G. (1996). Clarifying the EOconstruct and linking it to performance. Academy of Management Review, 21(1), 135-172. https://doi.org/10.5465/amr.1996.9602161568

Lumpkin, G.T., \& Dess, G.G. (2001). Linking two dimensions of EOto firm performance: The moderating role of environment and industry life cycle. Journal of Business Venturing, 16(5), 429-451. https://doi.org/10.1016/S0883-9026(00)00048-3

Lyon, D.W., Lumpkin, G.T., \& Dess, G.G. (2000). Enhancing EOresearch: Operationalization and measuring a key strategic decision making process. Journal of Management, 26(5), 1055-1085. https://doi.org/10.1016/S0149-2063(00)00068-4

Mangal, S.K., \& Mangal, S. (2013). Research methodology in behavioral sciences. Delhi: PHI Learning Private Limited.

Martin, D.M. (2009). The entrepreneurial marketing mix. Qualitative Market Research: An International Journal, 12(4), 391-403. https://doi.org/10.1108/13522750910993310 
Martin, J. (1992). Culture in organizations: Three perspective. Oxford: Oxford University Press.

Martin, J. (2002). Organizational culture: Mapping the terrain. Thousand Oaks: Sage Publication. https://doi.org/10.4135/9781483328478

Matthews, C.H., \& Scott, S.G. (1995). Uncertainty and planning in small and entrepreneurial firms: An empirical assessment. Journal of Small Business Management, 33(4), 34-53.

Miles, M., Hazeldine, M.F., \& Munilla, L.S. (2004). The 2003 AACSB accreditation standards and implications for business faculty: A short note. Journal of Education for Business, 80(1), 29-34. https://doi.org/10.3200/JOEB.80.1.29-34

Miles, M.P., \& Arnold, D.R. (1991). The relationship between marketing orientation and entrepreneurial orientation. Entrepreneurship Theory and Practice, 15(4), 49-65. https://doi.org/10.1177/104225879101500407

Miller, D. (1983). The correlates of entrepreneurship in three types of firms. Management Science, 29(7), 770-791. https://doi.org/10.1287/mnsc.29.7.770

Morris, M., \& Paul, G.W. (1987). The relationship between entrepreneurship and marketing in established firms. Journal of Business Venturing, 2(3), 247-259. https://doi.org/10.1016/0883-9026(87)90012-7

Mulgan, G. (2007). Ready or not? Taking innovation in the public sector seriously. London: Nesta.

Naldi, L., Nordqvist, M., Sjöberg, K., \& Wiklund, J. (2007). Entrepreneurial orientation, risk taking and performance in family firms. Family Business Review, 20(1), 33-47. https://doi.org/10.1111/j.1741-6248.2007.00082.x

Pettigrew, A.M. (1994). On studying organizational culture. Administrative Science Quarterly, 24(4), 570-581. https://doi.org/10.2307/2392363

Phelan, S.E., Johnson, A.T., \& Semrau, T. (2013). Entrepreneurial Orientation in public schools: The view from New

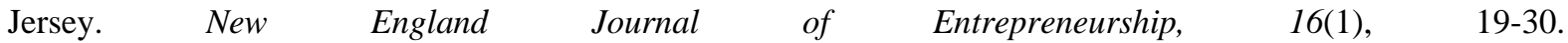
https://doi.org/10.1108/NEJE-16-01-2013-B002

Reid, G.J. (1989). Measuring government performance: The case of government waste. National Tax Journal, 42(1), 29-44. Retrieved from http://www.jstor.org/stable/41788771

Reynolds, P.D. (1997). New and small firms in expanding markets. Small Business Economic, 9(1), 79-84. https://doi.org/10.1023/A:1007916217140

Saunders, M., Lewis, P., \& Thornhill, A. (2012). Research methods for business students (6th ed.). England: Pearson Education Limited.

Schein, E.H. (1985). Organisational culture and leadership. London: Jossey-Bass.

Scott, R. (1995). Institutions and organizations. Thousand Oaks: Sage.

Stevenson, H.H., Roberts, M.J., \& Grousbeck, H.I. (1985). New business venture and the entrepreneur (2nd ed.). Homewood, IL: Richard D. Irwin.

Tabachnick, B.G., \& Fidell, L.S. (2007). Using multivariate statistics (5th ed.). Boston: Allyn \& Bacon.

Teofilovic, N. (2002). The reality of innovation in government. The Innovation Journal: The Public Sector Innovation Journal, 7(3), 1-30.

Van-der Merwe, S., \& Malan, J. (2013). An Assessment of the impact of entrepreneurial Orientation on the success of selected public secondary schools. Management Dynamics, 22(4), 20-37. Retrieved from http://hdl.handle.net/10520/EJC145860

Wiklund, J. (1998). Entrepreneurial Orientation as predictor of performance and entrepreneurial behaviour in small firms-longitudinal evidence. In P.D. Reynolds, W.D. Bygrave, N.M. Carter, S. Menigart, C.M. Mason, \& P.P. McDougall (Eds.), Frontiers of Entrepreneurship Research (pp.283-296). Wellesley: Babson College.

Yildirim, H., \& Saygin, S. (2011). Effects of owners' leadership style on manufacturing family firms' entrepreneurial Orientation in the emerging economies: An empirical investigation in Turkey. European Journal of Economics, Finance and Administrative Sciences, 32(32), 147-153.

Yusuf, A. (2002). Environmental uncertainty, the entrepreneurial Orientation of business ventures and performance. International Journal of Commerce \& Management, 12(3/4), 83-103. https://doi.org/10.1108/eb047454

Zahra, S.A. (1991). Predictors and financial outcomes of corporate entrepreneurship: A taxonomical approach. Journal of Business Venturing, 6(4), 259-285. https://doi.org/10.1016/0883-9026(91)90019-A 


\section{Appendices}

Appendix 1. Items of entrepreneurial orientation after EFA

\section{Factor 1: Innovation}

We regularly add new services $\&$ facilities.

We place a great emphasis on new innovative services $\&$ facilities.

We have over the past two years expanded the number of services \& facilities.

Innovation 01

Innovation 02

Innovation 03

The organisation's leadership always tries to maximise the value of opportunities without placing a stain on existing models, structures or resources.

The organisation's management is open to personal ideas and suggestions.

Innovation 09

We continuously strive towards new opportunities.

There is a great emphasis on innovation for the successful future existence and success of the institution.

Over the past few years, the changes to the services \& facilities were dramatic.

There is a strong correlation between the number of new ideas that are generated and the number of ideas that are successfully implemented.

There is a strong emphasis on the sustained improvement of services \& facilities.

\section{Factor 2: Autonomy}

I have sufficient autonomy in my work without continues supervision to do my work.

Managers are allowed to make decisions without having to go through an elaborate justification and approval process.

I seldom need to follow the same work procedures to work methods during the execution of my most important tasks.

Our organisation allows me to be creative and offers me the opportunity to experiment with new methods in my work.

Managers are encouraged to manage their own work and portfolio and there is flexibility when problems are solved.

There is a great emphasis on innovation for the successful future existence and success of the institution.

The organisation is often to establish new services facilities.

\section{Factor 3: Risk Taking}

Employees are often encouraged to take calculated risks pertaining to new ideas.

In general, the organisation has a strong inclination towards high-risk projects.

During times when the organisation is confronted with uncertain decisions, we often have a very strong stance in order to maximise the possibility of opportunities within the uncertainty.

The term "risk-taker" is considered as positive attribute for employees at the organisation.

Projects with a calculated risk are highly valued even if it does not work out as initially planned.

The organisation is continually seeking new services and facilities.

Innovation 11

Innovation 04

Innovation 08

Innovation 05

Innovation 06

Innovation 07

Autonomy 01

Autonomy 03

Autonomy 05

Autonomy 02

Autonomy 04

Innovation 08

Proactivness 01

Risk Taking 03

Risk Taking 02

Risk Taking 01

Risk Taking 05

Risk Taking 04

Proactivness 03

Proactivness 05

Proactivness 04

Managers have a strong tendency to follow the leader in introducing new services and facilities.

\section{Factor 3: Proactivness}

The organisation is continually seeking new services and facilities.

Proactivness 03

Typical of our organisation, actions are initiated to which others can react.

Proactivness 02

The rate of change has accelerated rapidly in rendering of services and facilities.

Proactivness 05

Managers have a strong tendency to follow the leader in introducing new services and facilities.

The organisation is often to establish new services facilities.

There is a strong emphasis on the sustained improvement of services \& facilities.

Proactivness 04

Proactivness 01

Innovation 07 
Appendix 2. Items of organisation's performance after EFA

\begin{tabular}{|c|c|}
\hline \multicolumn{2}{|l|}{ Factor 1: Internal Environment Effectiveness } \\
\hline Within the organisation, employees' behaviour is addressed. & Environment 05 \\
\hline $\begin{array}{l}\text { Within the organisation, there is a trusting relationship between beneficiaries, employees } \\
\text { and management team. }\end{array}$ & Environment 02 \\
\hline The organisation's environment is safe and organised. & Environment 09 \\
\hline $\begin{array}{l}\text { Within the organisation, there is a willingness to establish organisational changes to the } \\
\text { benefit of employees. }\end{array}$ & Environment 08 \\
\hline $\begin{array}{l}\text { Within the organisation, there are definitive signs of collegiality and professionalism. } \\
\text { Within the organisation, there is a focus on basic skills of employees. }\end{array}$ & $\begin{array}{l}\text { Environment } 06 \\
\quad \text { Environment } 07\end{array}$ \\
\hline \multicolumn{2}{|l|}{ Factor 2: Ability to Achieve Organisation's Goals } \\
\hline Within the organisation, there is a presence of administrative leadership. & Environment 01 \\
\hline $\begin{array}{l}\text { Within the organisation, there is a mutual respect between employees and management } \\
\text { team. }\end{array}$ & Environment 03 \\
\hline The goal \& objectives' of the organisation are regularly reviewed. & Goals 04 \\
\hline The focus of the organisation is achieved. & Goals 05 \\
\hline High expectations are placed on employees pertaining to achievement. & Goals 02 \\
\hline The organisation is committed to high performance expectation. & Goals 01 \\
\hline I know the organisation's goal and objectives. & Goals 03 \\
\hline Within the organisation, working time is used effectively and efficiently. & Environment 04 \\
\hline The organisation's environment is safe and organised. & Environment 09 \\
\hline \multicolumn{2}{|l|}{ Factor 3: Individual Self Development } \\
\hline $\begin{array}{l}\text { Within the organisation, there is a clear connection between training programmes and } \\
\text { out-put of the training programmes. }\end{array}$ & Development 03 \\
\hline Within the organisation, there is a sustainable employees' development programme. & Development 02 \\
\hline All employees were part of the organisation development plan. & Development 04 \\
\hline $\begin{array}{l}\text { Within the organisation, employees are continuously encouraged to improve their } \\
\text { qualifications. }\end{array}$ & Development 01 \\
\hline $\begin{array}{l}\text { Within the organisation, there is a willingness to establish organisational changes to the } \\
\text { benefit of employees. }\end{array}$ & Environment 08 \\
\hline
\end{tabular}

